\title{
The environmental control indoors with application of moisture-regulating plasters
}

\author{
Viacheslav Konkov \\ Institute Belniis Republican Unitary Research Enterprise for Construction, Belarus, \\ e-mail:konkov@belniis.by
}

\begin{abstract}
Provision of comfortable conditions in the premises with simultaneous optimization of costs throughout the life cycle of the building was the main objective of the study. The analysis of the world engineering practice of troweling compounds with high moisture-regulating ability is performed. Information on the features of the manufacture of plasters with moisture-regulating ability is given. Usage of expanded aggregates that have the ability to quickly collect, store, and then slowly release moisture is an effective way to regulate moisture in living areas of buildings under construction as well as of newly erected ones. As a result of this study, it has been shown that it is possible to produce environmental control in residential premises not only through the operation of costly air conditioning systems that consume a significant amount of power, but also by using accumulating and easily releasing moisture building materials, providing a dampening effect. Studies have been carried out and troweling compounds with a high moisture-regulating ability with the use of domestic components have been developed, allowing, in addition to the above-mentioned purposes, to reduce the risk of water vapour condensation on the walls and the occurrence of fungi and mould in the room.

Keywords: troweling compounds, moisture-regulating ability, expanded aggregates, modifying additives, environmental control, moisture storage, dampening effect, mould formation prevention.
\end{abstract}

\section{Introduction}

After the increase of statutory indicators of the heat transfer resistance of the enclosure of buildings and, accordingly, the reduction of the cost of heat energy to maintain comfortable conditions in them, the questions of air quality decreasing indoors and a significant increase in its humidity began to appear.

This was the result of the fact of neglecting by inhabitants the installation of supply and exhaust forced ventilation systems with heat recuperation during the repair and reconstruction of their rooms, in order to minimize financial costs. In addition, these systems were disconnected in some cases in newly constructed buildings in the process of their operation, trying to minimize heating costs during the cold season. And in the cases, where such systems were absent, sometimes ordinary fresh air valves were simply sealed, trying to limit the flow of cold air into the room.

The carried out explanatory work, and even the handing over of a special manual on the proper operation of heating and ventilation systems to each apartment owner did not always lead to the desired result.

Further on, in the process of operation, the same inhabitants presented claims to developers and construction organizations, connected with a decrease in the comfort of living, as well as the formation of mould on the walls and ceiling, which could lead to a decrease in 
the commercial attractiveness of residential buildings. The study of this issue confirmed that such negative phenomena are observed, as a rule, in the places where the owners of apartments do not provide the correct modes of their functioning.

We have made an attempt to develop a set of constructive and technological solutions that can significantly reduce the consequences of the above situations, as well as minimize the influence of subjective factors.

For this purpose, an analysis of the existing world engineering practice was carried out, which has shown that the object in view could be achieved by using finishing materials capable of accumulating a part of the moisture contained in the air with increased humidity in the room, followed by its return in the case of moisture reduction.

For a number of years, researches on the possibility of environmental control in the rooms of buildings that are under construction as well as of newly erected ones, through a number of innovative solutions, including the improvement of finishing materials and methods for their application, have been carried out at Institute BelNIIS Republican Unitary Research Enterprise for Construction.

This article presents the results of research in relation to buildings made of small piece materials (bricks and ceramic stones).

\section{Localization of areas of increased humidity in living quarters}

Given that any additional engineering solution or the use of material with special properties can lead to an increase in the cost of buildings and, therefore, to a certain decrease in competitive opportunities in the real estate market, we adhered to the principle of reasonable sufficiency. To this end, the work has been carried out to localize areas of increased humidity in living quarters.

It is established that significant moisture liberation occurs as a result of people's vital activity and various processes (cooking, washing, etc.). At the same time, the supply of water vapour from different sources is very different [1].

Table 1 lists some sources of moisture liberation in buildings and their values.

Table 1. Intensity of moisture liberation in buildings

\begin{tabular}{ll}
\hline Source of moisture liberation & Intensity of moisture liberation, 1/day \\
\hline $\begin{array}{l}\text { People } \\
\text { (one-man vapour emission) }\end{array}$ & $\begin{array}{l}0.75 \text { (sedentary activity) } \\
1.2 \text { to } 5 \text { (hard labour) }\end{array}$ \\
\hline Air humidifiers & 2 to 20 \\
\hline Hot bath & 2 to 20 \\
\hline Mopping & 0.2 \\
\hline Dish washing & 0.5 \\
\hline Food preparing for 4 persons & 0.9 to 2 (3 with allowance of gas) \\
\hline Automatic defrosting refrigerator & 0.5 \\
\hline Face washing/hand washing (per 1 person) & 0.2 to 0.4 \\
\hline Shower (per 1 person) & 0.5 \\
\hline Seasonal moisture-yielding ability (or new construction & $\begin{array}{l}3 \text { to } 8 \text { (depends on the structure of the } \\
\text { building) }\end{array}$ \\
\hline
\end{tabular}


Thus, when designing a finishing layer, a moisture-regulating plaster can be used in kitchens, bathrooms and adjacent areas. The use of air humidifiers with reduced humidity also loses relevance due to the desorption of moisture from the finishing layer into the room, creating a dampening effect.

The accumulating capacity and vapour permeability of plasters with a high moistureregulating ability ensure balanced air humidity in the room and a comfortable environment. In this case, the higher the ability of walls and ceilings to accumulate heat is, the more uniform the room temperature is. Also the minimum difference between the room temperature and the wall surface temperature is an essential advantage.

In a residential building, there is a constant process of moisture migration from the inside out through the walls when the outside air temperature is below room temperature. The amount of outgoing water vapour depends on the difference in temperature and humidity outside and inside the room. At the same time, the lower the humidity is, the less the probability of formation of internal condensate, mould and fungi is.

Relatively stable air humidity in the room has a significant impact not only on the health of inhabitants, but also on power consumption in the house: the drier the air is, the less heat is required to heat the room.

In addition, moisture causes or accelerates the electrochemical corrosion of metal products and parts; chemical damage to gypsum facing, ceiling slabs, wooden materials; changing the colour of the architectural details of the building; change in the volume of construction materials (swelling, buckling, shrinkage), etc.

\section{Designing of plasters with moisture-regulating ability}

During the research, the primary attention was paid to achieving the maximum moisture-accumulating capacity of the plaster materials and ensuring their smooth moisture yielding during the humidity reducing in the room.

The analysis of engineering practice showed that in order to solve this problem, the Sto AG company (Switzerland), in cooperation with the Swiss federal laboratory for materials science and technology, Empa [2], developed a special plaster for the walls. The ability to absorb moisture from the air much more efficiently than the vast majority of the currently existing traditional lime plasters is its distinctive feature. When creating it, the developers adhered to the following criteria: the plaster should be moisture-regulating, made on a mineral basis, easy to use and not too expensive, in comparison with existing analogous ones.

This plaster for walls is capable of absorbing 90 grams of water vapour per one $\mathrm{m}^{2}$, which is one third higher than that of the best clay-based plaster. As noted by the developers, the moisture-regulating plaster should be applied to walls $10-20 \mathrm{~mm}$ in thickness, in order to achieve the maximum degree of moisture absorption.

The Schaefer Krusemark construction company (Germany) [3] has created several types of moisture-regulating plaster. High-quality calcined sands and special granular lightweight aggregates, mineral binders, additives and agents improving the technical parameters of the final product are used for its production as an aggregate.

Qualitative clay-based plaster is made by Womersley's Ltd (UK) [4], lime-based plaster is produced by KeimFarben GMBH (Germany) [5], etc.

These troweling compounds have the highest possible vapour permeability and good adhesion. The higher the vapour permeability index is, the better the wall breathes and the higher the process intensity of sorption and desorption of moisture is. 
The creation of domestic moisture-regulating troweling compounds with the maximum use of components available in our market was one of the main tasks of the study. This article presents one of the stages, at which the properties of plasters based on cement binders were examined when used in buildings with walls made of small piece materials (brick and ceramic stones).

It is established that the moisture-regulating plaster coating of walls must meet the following requirements:

- air entrainment of the mortar mixture must be at least $20 \%$;

- porosity of plaster mortar must be not less than $45 \%$;

- adhesion with wall material must be at least $0.2 \mathrm{MPa}$;

- the average density of the mortar should be not more than $1100 \mathrm{~kg} / \mathrm{m}^{3}$;

- the coefficient of vapour permeability of plaster layers should be not less than $0.06 \mathrm{mg} / \mathrm{m} \mathrm{h} \mathrm{Pa}$;

- moisture absorption at the maximum humidity of air should be not less than $80-90 \mathrm{~g} / \mathrm{m}^{2}$;

- the moisture release of the plaster coating should be carried out within several hours.

At first, the types and properties of expanded aggregates were studied, which can be used most efficiently to solve the problem posed [6].

Expanded aggregates have, to varying degrees, the ability to quickly collect, store, and then slowly release moisture, levelling the diurnal and seasonal fluctuations in humidity. Thus, a fairly simple and inexpensive compound using various expanded aggregates will be very effective in maintaining the optimum moisture regime in houses.

Mineral binders (Portland cement M500 D 20, hydrated lime), modifying additives (Micelles FMC 2250 methylcellulose, Berolan LPW 1 air-entraining additive), fine-dispersion fillers (carbonate of lime, dolomite), aggregate (quartz sand), expanded aggregates (porover, expanded vermiculite, expanded perlite, expanded polystyrene in granules, expanded clay sand), and Arbocel PWC 500 cellulose fibre were used in the present work to develop moisture-regulating plasters.

This article presents the results of studies of various compositions of moisture-regulating plasters. In particular, the strength characteristics of a cement binder with various contents of fine-dispersion fillers (dolomite, carbonate of lime) was checked.

As a result of the tests, it was found that the compressive strength does not change with a carbonate of lime and dolomite content of not more than 20 mass $\%$. When the content of dolomite is increased, the strength characteristics of the binder is reduced. An increase in the content of carbonate of lime in mortars of more than $20 \mathrm{wt} . \%$ leads to an insignificant decrease in the compressive strength.

Consequently, the use of carbonate of lime as a filler in moisture- regulating plasters is preferable.

In addition, as a result of the tests, it has been established that when using dolomite as a fine-dispersion filler, the formation of salt efflorescences on the plaster coating is possible.

The following methods of creating a porous structure of materials were used for further optimization of plaster mortars:

- the involvement of air and the formation of air pores directly in the mortar;

- preparation of the mortar with the introduction of a light expanded aggregate.

A Berolan LPW 1 pore former, stabilizing the mechanical capture of air, was used in an amount of 0.01 to $0.06 \%$ by weight of the dry mixture to pore plaster mortars by involving air and air pores forming directly in the mortar.

It is established that the air entrainment increases up to $20 \%$ when the content of the pore former in the mortar is not less than $0.02 \%$. 
In the present work, cellulose derivatives, namely Micelles FMC 22501 methylcellulose (MC), were used to increase air entrainment. It is established that when introducing the above additive into the plaster mixture, air entrainment reaches values of $14-15 \%$.

Expanded aggregates represent one of the main components in the development of moisture-regulating plasters. The type of expanded aggregate is determined by the maximum grain size and shape, grain composition, fine particles content and porosity.

The density reducing of plaster mortars is the main indicator of the mortars quality when using these aggregates.

Artificial expanded aggregates differ from aggregates obtained from industrial wastes by the stability of the composition and properties, and therefore aggregates of this category are recommended for use in the composition of mortars for the production of moisture-regulating plasters.

The following expanded aggregates were used:

- expanded perlite, having grain size of no more than $1.5 \mathrm{~mm}$ and bulk density of no more than $100 \mathrm{~kg} / \mathrm{m}^{3}$;

- expanded vermiculite, having grain size of no more than $1.5 \mathrm{~mm}$ and bulk density of no more than $150 \mathrm{~kg} / \mathrm{m}^{3}$;

- expanded clay sand, having grain size of no more than $5 \mathrm{~mm}$ and bulk density of $640 \mathrm{~kg} / \mathrm{m}^{3}$;

- expanded polystyrene is a granular bulk material obtained from an expandable polystyrene into which an air pore former is introduced, having a bulk density of $35 \mathrm{~kg} / \mathrm{m}^{3}$;

- porover is a specially processed, granulated glass in the form of small hollow balls with a dispersion of $0.1-0.3$ and $0.2-0.5 \mathrm{~mm}$. It is a lightweight, durable, chemically resistant, non-flammable material.

An aggregate has a significant effect on the setting time of a mortar. The aggregate introduced into the cement paste, due to the manifestation of surface forces, shortens the period of the structure formation, and the higher the content of the aggregate and its specific surface is, the greater its influence is.

The presence of an aggregate significantly affects the hardening conditions of paste matrix. In the mortar, the interaction of cement with water and its solidification takes place in thin interlayers between the grains of the aggregate in constant interaction with it. The aggregate increases the water-retaining capacity of the cement paste, limits shrinkage deformations, promotes the formation of a crystalline scaffold of paste matrix, influences the temperature and humidity changes in the hardening of paste matrix.

The study of air entrainment and moisture sorption for 3 hours of exposure at a moisture content of $98 \pm 2 \%$ and a temperature of $20 \pm 2^{\circ} \mathrm{C}$ of moisture-regulating plasters based on a cement binder with various lightweight fillers showed that, in this case, a moistureregulating plaster in which expanded vermiculite is used as an expanded aggregates has the highest air entrainment.

In absolutely dry material the pores and capillaries are filled with air. However, if the building material is in air containing water vapour, a certain amount of water vapour penetrates into the air pores and condenses on their walls until an equilibrium moisture is established, which depends on the partial pressure of the vapour in the ambient air.

The change in the content of water vapour in the moisture-regulating plaster based on a cement binder is shown in Figure 1. 


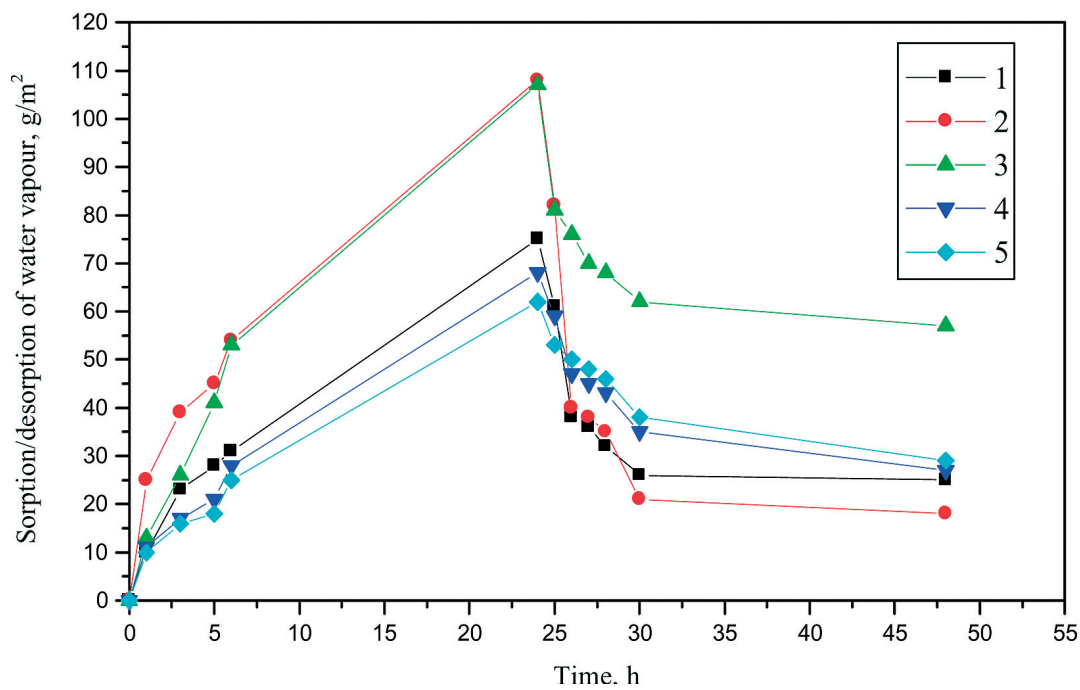

Fig. 1. Change in the content of water vapour in the plaster vs. holding time: $(1-24) \mathrm{h}-$ moisture sorption at $(98 \pm 2) \%$ humidity; $(24-48) \mathrm{h}$ - desorption of moisture at $(60 \pm 5) \%$ of humidity $1-10 \%$ of expanded perlite $+0.1 \%$ of MC; $2-10 \%$ of expanded vermiculite $+0.1 \%$ of MC; $3-10 \%$ of expanded vermiculite $+0.3 \%$ of MC; $4-20 \%$ of porover $+0.1 \%$ of MC; $5-5 \%$ of expanded polystyrene $+0.1 \%$ of MC.

Thus, the moisture-regulating plaster, containing $10 \%$ of vermiculite is an optimal compound.

Arbocel PWC 500 cellulosic fibres made of natural raw materials were used as the thickener, reinforcing agent and adsorbent to further optimize the composition of the moisture-regulating plaster. The dependence of the air entrainment of the moisture-regulating plaster with the expanded vermiculite on the content of the above cellulose fibre is shown in Figure 2.

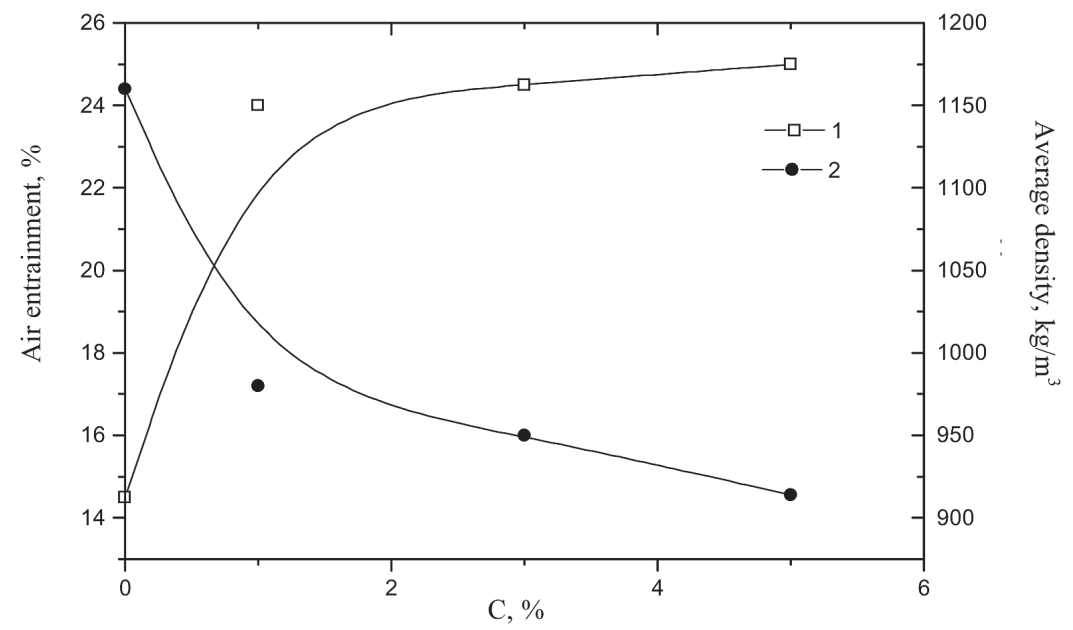

Fig. 2. Dependence of air entrainment (1) and average density (2) of moisture-regulating plaster with expanded vermiculite on the content of cellulose fibre 
The change in the content of water vapour in the moisture-regulating plaster containing expanded vermiculite, Micelles FMC 22501 methylcellulose, Berolan LPW 1 air entraining admixture, Arbocel PWC 500 cellulose fibre is shown in Figure 3.

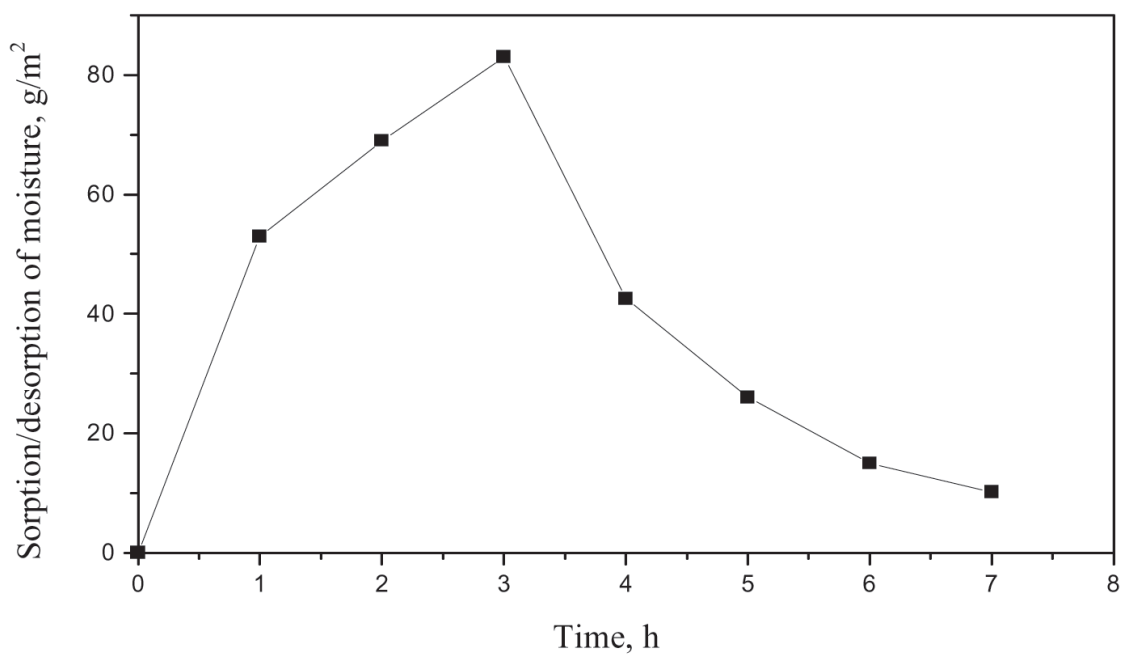

Fig. 3. Change in water vapour content vs. time. Exposition of (0-3) hours - moisture sorption; (3-7) hours - desorption of moisture

At the time of troweling compounds designing, it is necessary to take into account the fact that when they are applied to walls of brick or ceramic blocks, in contrast to concrete walls, moisture migration from the plaster layer to the wall array is possible during operation. In most cases, the amount of moisture migrating into the wall makes up 4-7\% of the sorbed water vapour, and the penetration depth does not exceed 10-15 $\mathrm{mm}$. This factor should also be taken into account when calculating the thermal resistance of building envelopes.

Thus, it has been established that cement plasters with a high moisture-regulating ability have a number of advantages over traditional cement plasters. First of all, these plasters actively "breathe". Their ability to damp the increased or decreased moisture content in indoor air is significantly better than that one of traditional plasters.

\section{Conclusion}

The analysis of the world engineering practice and conducted scientific research have shown the expediency of environmental control in the premises of residential buildings and industrial premises not only through the operation of expensive air conditioning systems that consume a significant amount of power, but also through the use of building materials, accumulating and easily releasing moisture.

The development of troweling compounds with a high moisture-regulating ability (based on the use of predominantly domestic components), which improve the comfort of a person in the room, reduce the risk of condensation of water vapour on walls and ceilings, and the appearance of fungi and mould was the result of the study. 


\section{References}

[1] Straube J.E. Simplified prediction of driving rain deposition. Proceedings of International Buildings Physics Conference. Eindhoven, 2000, pp. 375-382.

[2] Empa: NEST - exploring the future of buildings: plasters. [Electronic resource]. https://www.empa. $\mathrm{ch} /$ web/empa/.

[3] Schaefer Krusemark: Fertigmörtel. [Electronic resource]. http://www.schaefer-krusemark.de.

[4] Womersley's Ltd: Plasters. [Electronic resource]. http://www.womersleys.co.uk.

[5] KeimFarben GMBH: Plasters. [Electronic resource]. https://www.keim.com/choose-country.

[6] Zozulya P.V. Evaluation of the shape of fine aggregate particles for mortars. 4 Intl. Conf. "Batimix" - dry mix mortars for the XXI century: technology and business. Collection of papers. St. Petersburg, 2004, pp. 26-27. 